\title{
Vibration of Power Hand Tool and Discomfort Experience Among Malaysian Industrial Workers
}

\author{
Seri Rahayu K. ${ }^{1, a}$, Nurulhuda $A^{2, b}$ and Rohana $A^{3, c}$ \\ 1,2,3 Faculty of Manufacturing Engineering, \\ Universiti Teknikal Malaysia Melaka, Durian Tunggal, 76100 Melaka, Malaysia \\ Phone: +606-3316002, Fax: +606-3316411 \\ Phone: +606-3316447, Fax: +606-3316411 \\ a seri@utem.edu.my, ${ }^{\text {b }}$ nurulhuda@ymail.com, ${ }^{c}$ rohana@utem.edu.my
}

Keywords - Hand Arm Vibration, Handling vibrating tool, Grip Strength and Vibration

\begin{abstract}
In reality, people who worked with power vibrating tools exposed with the vibrated syndrome that effect their normal life especially who involved for long time period. Hand-arm vibration (HAV) is a widespread hazard in many industries and occupations involving the use of handheld power tools or hand-fed machines. This paper describes a research and observation on the vibrating hand tool. The objective of this study is to measure and compare the grip strength and hand arm vibration before and after using the Ready-Reckoned standard for industrial workers. Continually, an analysis is conducted due to the pain and discomfort experience that face by the workers. This research also do the analysis about the effects of the vibration to the worker's hand depend on the duration of handling the power hand tool. Hundred respondent was involved which 50 men and 50 women who had been identified as an industrial worker and working with power hand tools or machinery. The respondents were interviewed and answer Q-Survey that directly conducted at their workplace after doing the test. As the result, worker who works 8 hours per day, the exposure limit value (ELV) is $5 \mathrm{~m} / \mathrm{s}$, it can cause fatal effects. Most of workers suffered with fingers that gone white on cold exposure and weakness in hand grip.
\end{abstract}

\section{Introduction}

In the industry, power hand tool is one of the common tools that have been used by the worker almost every day. For the workers that handled the power hand tool such as hammer, hand grinder and hand drill in their daily job, they will confront the physical stress such as hand-arm vibration. Vibration that produced by the vibration power hand tool enters the body of the user from the organ in contact with vibrating equipment [1],[2] and [9]. Hand-Arm Vibration (HAV) is widespread hazard in many industries and occupations involving the use a handheld power tools (such as grinders or hammer drills), hand guided machinery (such as lawn mowers and plant Compactors) or hand-red machines (such as pedestal grinders) [3],[5] and [6]. Prolonged and regular exposure to this vibration can affect the operator's health, resulting in pain and disabling disorder of the nerves, blood supply, joint and muscles of the hand and arms. These disorders are collectively known as hand arm vibration syndrome (HAVs). Hand-Arm Vibration Syndrome (HAVS) and Carpal Tunnel Syndrome are the common disease that relates to the vibration in power hand tools [3], [4] and [5]. Hand-Arm Vibration Syndrome, it is usually caused by the frequent use of vibrating hand tools that have the frequency range between $8 \mathrm{~Hz}$ and $1500 \mathrm{~Hz}$ with the most hazardous frequencies are from $100 \mathrm{~Hz}$ to $150 \mathrm{~Hz}$ [4]. The persons with this syndrome will have common symptoms such as tingling, numbness, loss of feeling and pain in the fingers or hands. They may experience a gradual decrease in their grip strength, reduced dexterity, and both their hand and arm muscles tire easily. They also may have a cold feeling of the fingers and possibly whitening of the fingers beginning at the tips [7] and [8]. These symptoms are initially intermittent but later become continuous if exposure continues. Because of this problem, this study wants to describe a research and observation on the vibrating hand tool. The objective of this study is to measure and compare the 
grip strength and hand arm vibration before and after with the Ready-Reckoned standard to the industrial workers.

\section{Methodology}

A hundred respondents selected which involved 50 men and 50 women who had been identified as an industrial workers and working with power hand tools or machinery. The power hand tools used in this study are grinder, hand drill, electric screwdriver and cordless screwdriver. Volunteers with age 20 to 50 years were chosen to take parts in this experiment and survey questionnaire. In this study, the questionnaire and physical test has been used to collecting the data. The dynamometer was used to measure the hand grip force of the selected industrial workers that working with vibrating hand tool. The hand grip test was conducted before and after the industrial workers do their job using the vibrating hand tool. While doing the test, the selected participant was asked to grab the dynamometer with a neutral grip and take a deep breath. The experiment took about 20 minutes to finish. After finish the experiment the volunteers should answer the questionnaire. The questionnaire have 2 sections: first section is about demography information and section 2 is more about their present jobs, discomfort experience on the hand (finger, wrist and shoulder) and tools usually used. All the data taken need to transfer to a Quests Suite Professional II to analyze the data. Finally a decision is being made guided by a standard table Ready-Reckoner.

\section{Result}

Table 1 shows the vibration equipment that used by the worker when doing their job. The responses that used grinder have higher percentage was $37 \%$, follow by hand drill was $27 \%$, electrical screwdriver was $22 \%$, both grinder and hand drill was $9 \%$ and percentage for cordless screwdriver was only $5 \%$. This data shows, the grinder are most popular hand tool use in many job.

Table 1: Vibrating equipment used in any job.

\begin{tabular}{|l|c|c|c|}
\hline Vibration Equipment Used & Male & Female & Percentage \\
\hline Grinder & 28 & 9 & $37 \%$ \\
\hline Hand Drill & 17 & 10 & $27 \%$ \\
\hline Electric Screwdriver & 0 & 22 & $22 \%$ \\
\hline Grinder \& Hand Drill & 5 & 4 & $9 \%$ \\
\hline Cordless Screwdriver & 0 & 5 & $5 \%$ \\
\hline
\end{tabular}

Histogram graph in Figure 1 shows the present job title of the participant. There were 9 types of job for 100 respondents that involved in this research. Technician appears as the largest group with 23 male and 19 female respondents. It represents $42 \%$ from total participants. Operator and welder also indicate a high number which are $23 \%$ and $11 \%$ respectively but the operator post was monopolized by women while welder post was monopolized by men. Machinist, workshop instructor, and wireman also monopolized by single gender with low percentage which is 5\%, 3\%, and $1 \%$ respectively. 6 male and a female respondent were work as maintenance and they represent $7 \%$ from total participants. With a male and 3 female respondent work as team leader and 3 male and a female respondent work as supervisor, they contribute $4 \%$ each to the total participants.

Hand grip force is one of the factor give effect while worker using the handling vibrating tool. Figure 2 shows the hand grip force before and after using the vibrating tool being different. The grip forces are decreased after vibration. 


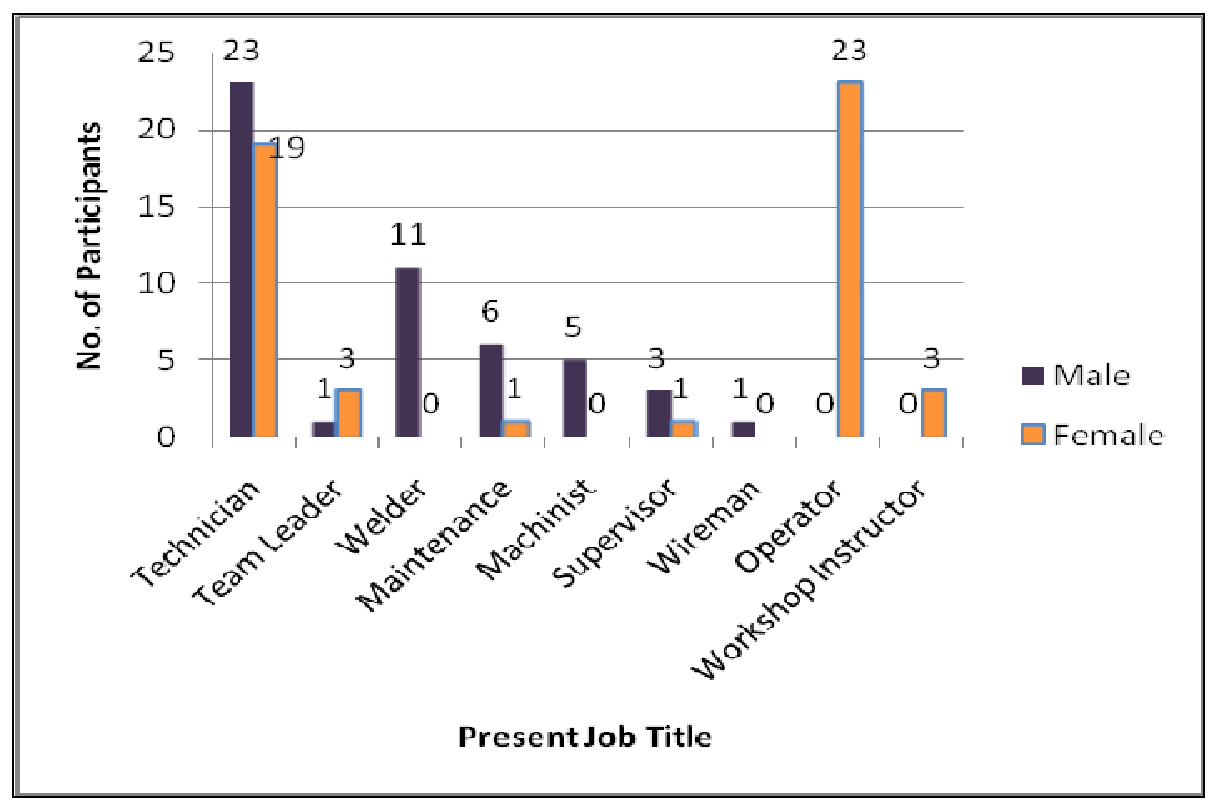

Figure 1: Present job of the respondents.

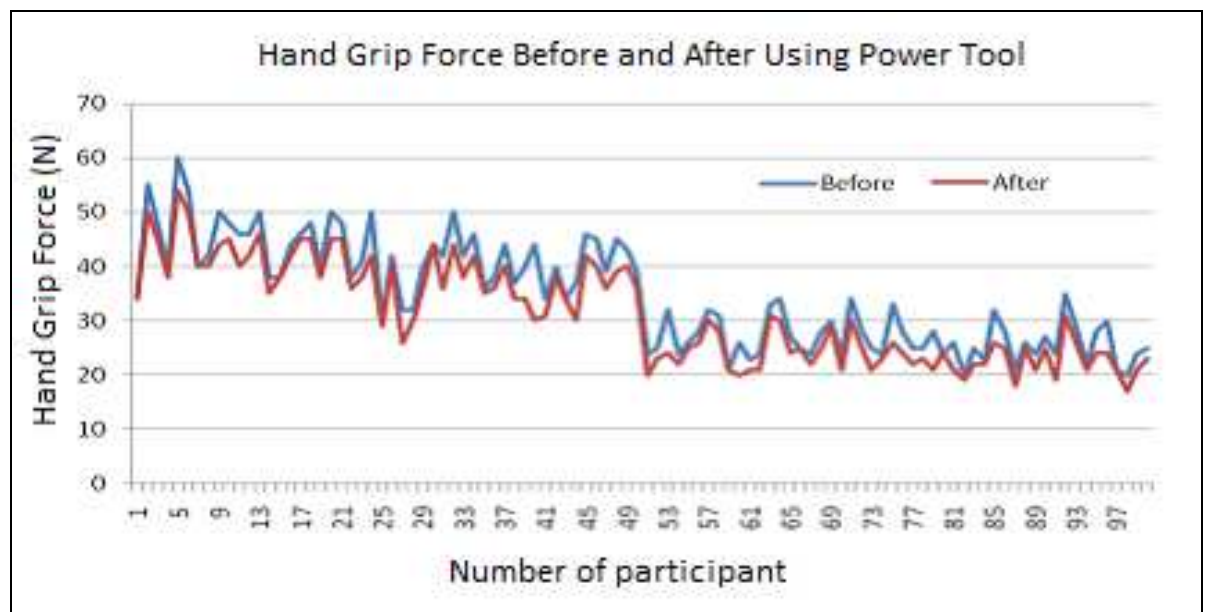

Figure 2: Hand grip force for 50 men and 50 women after and before using power hand tool.

Two factors are needed to analysis the HAVS which is the vibration magnitude (level) and exposure time. The Ready-Reckoner cover range of vibration magnitudes up to $40 \mathrm{~m} / \mathrm{s}^{2}$ and a range of exposure times up to 10 hours. The exposure for different combinations of vibration magnitude and exposure time are given in exposure points instead of value is $\mathrm{m} / \mathrm{s}^{2} \mathrm{~A}$. Using the hand arm vibration exposure calculate results shows, if an individual exposed to vibration for a long period of time, the daily exposure of hand arm vibration will increase. This is because ELV (exposure limit value) and EAV (exposure action value) decrease with time.

\section{Discussion}

The hardness of material that is been grinding also can lead to this situation. The rougher or the harder the surface of the grinding material gives the higher value of the vibration. This is true when two hard surface are touched they give out more force than softer material. The machine work rate also gives the major effect of the hand arm vibration. The work rates may be too high which can be fatal for the user in the long term. It gives out too much frequency will increase the vibration. The individual grinding skill itself is other factor. The appropriate skill is important in determine the vibration whether it slow or fast. If the skill is correct the vibration is low while the other is vice versa. For health description, the industrial workers will be asked about the present symptoms of Hand-Arm Vibration Syndrome (HAVS) and Carpal Tunnel Syndrome such as present of tingling 
and numbness in the fingers and also the present of white fingers symptom. They also will be asked about their awareness to the hazard of vibration. Table 2 showed the percentage of respondent who experienced with the effect of vibration tool through answering 'Yes' in the questionnaire.

Table 2.0: Types of Syndrome faced by workers.

\begin{tabular}{|l|c|}
\hline Type of Syndrome & Percentages \\
\hline Tingling more than 20 minutes & $11 \%$ \\
\hline Tingling at any other time & $11 \%$ \\
\hline Wake at night with pain, tingling and numbness & $2 \%$ \\
\hline Numb more than 20 minutes & $36 \%$ \\
\hline Fingers gone white on cold exposure & $90 \%$ \\
\hline Difficult to re-warming when leaving the cold & $34.4 \%$ \\
\hline Fingers go white at any other time & $15 \%$ \\
\hline
\end{tabular}

Table 3.0: Medical History of Workers.

\begin{tabular}{|l|c|}
\hline Suffer from weakness in hand grip & $46 \%$ \\
\hline Injured at neck, shoulder, arm or hand & $19 \%$ \\
\hline Surgery received at neck, shoulder, arm or hand & $21.1 \%$ \\
\hline
\end{tabular}

Table 4 shows a T-Test result of significant for the hand grip strength between male and female respondents and correlation for effects and duration of handling the vibration tool by the workers. The relationship between the hand grip strength and gender of all 100 respondents was significant because the value was less than 0.05 . The correlation for male and female respondents was 0.97 . It was a positive value so we can say that the hand grip strength value for both male and female respondents will rise and fall together.

Table 4: Correlation and Significant of Hand Grip Strength and Gender.

\begin{tabular}{|c|c|c|c|}
\hline Gender & Sample Size & Correlation & Significant \\
\hline Male and Female & 100 & 0.973594 & $1.51669 \mathrm{E}-26$ \\
\hline
\end{tabular}

According to table 5 on T-Test for effects and duration of handling vibration below, indicates no significant difference between the effects and the duration of handling vibration tool because the significant value was more than 0.05 . For the correlation, all effects show positive value. So we can say that the longer the duration of handling the vibration tool, the higher the number of the respondents that had the vibration-related symptom such as tingling, numbness, and decreased hand grip strength.

Table 5: Correlation and Significant of Effects and Duration of Handling Vibrating Tool.

\begin{tabular}{|c|c|c|c|}
\hline Effects & Sample Size & Correlation & Significant \\
\hline Tingling & 100 & 0.410997 & 0.405023 \\
\hline Numbness & 100 & 0.7882408 & 0.2306357 \\
\hline Decreased Hand Grip Strength & 100 & 0.834430987 & 0.196522432 \\
\hline
\end{tabular}

\section{Conclusion}

The result analysis shows that most of workers have been suffered and experience one or more syndromes in their job. Workers facing with pain and discomfort experienced such as tingling and numbness in the fingers, white fingers symptom, suffering from weakness in hand grip and injury at 
neck, shoulder, arm, or hand have been asked to the respondents. For this research, the effects of the vibration to the worker's hand was measured by asking the respondents about the present symptoms of Hand-Arm Vibration Syndrome (HAVS) and Carpal Tunnel Syndrome such as present of tingling and numbness in the fingers and also the present of white fingers symptom.

\section{References}

[1] Alaska Department of Labor and Workforce Development, 2011. Physical Agent Data Sheet: Hand-Arm Vibration. [Online]. Available at: www.labor.alaska.gov/lss/pads/hand-arm.html [Accessed on 8 October 2011]

[2] Canadian Centre for Occupational Health and Safety (CCOHS), 2008. Vibration-Introduction. [Online]. Available at www.ccohs.ca/oshanswers/phys_agents/vibration/vibration_intro.html [Accessed on 8 October 2011]

[3] Burstrom, L., et al., 2009. Occupational Exposure To Vibration From Hand-held Tools: A Teaching Guide On Health Effects, Risk Assessment and Prevention, Geneva: WHO Press.

[4] Construction Solution, 2011. Hand-Arm Vibration: Hazard Analysis. [Online]. Available at: www.cpwrconstructionsolutions.org/masonry/hazard/128/vibrate-and-compact-concrete-orgrouthand- arm-vibration.html [Accessed on 7 October 2011]

[5] Erica, W., and Lina, L., 2005. Hand-Arm Vibration Syndrome. Canadian Medical Association, 172(8), pp. 1001-1002.

[6] Health and Safety Executive, 2005. Control the risk from hand-arm vibration. [Online]. Available at: www.hse.gov.uk/pubns/indg175.pdf [Accessed on 29 October 2011]

[7] Janet,T.K., et al., 2009. Ergonomics: Risk Factor-Vibration. [Online]. Available at: www.imana.org/IMA-NA-files-ccLibraryFiles-Filename-000000000427-5RiskFactorsVibration.pdf [Accessed on 21 October 2011]

[8] Nicola, M.W., et al., 2011. Hand Grip Strength: age and gender stratified normative data in a population-based study. [Online]. Available at: http://www.biomedcentral.com/1756-0500/4/127 [Accessed on 27 May 2012]

[9] Occupational Health Clinics for Ontario Workers Inc., 1990. Hand-Arm Vibration Syndrome (HAVS). [Online]. Available at: www.ohcow.om.ca/resources/handbooks/havs/HAVS.htm [Accessed on 30 October 2011] 